\title{
Influence of the ambient temperature on the cooling efficiency of the high performance cooling device with thermosiphon effect
}

\author{
Patrik Nemec ${ }^{1, *}$, Milan Malcho ${ }^{1}$ \\ ${ }^{1}$ University of Zilina, Faculty of Mechanical Engineering, Department of Power Engineering, Univerzitna 8215/1, 01026 Zilina, \\ Slovak republic
}

\begin{abstract}
This work deal with experimental measurement and calculation cooling efficiency of the cooling device working with a heat pipe technology. The referred device in the article is cooling device capable transfer high heat fluxes from electric elements to the surrounding. The work contain description, working principle and construction of cooling device. The main factor affected the dissipation of high heat flux from electronic elements through the cooling device to the surrounding is condenser construction, its capacity and option of heat removal. Experimental part describe the measuring method cooling efficiency of the cooling device depending on ambient temperature in range -20 to $40^{\circ} \mathrm{C}$ and at heat load of electronic components $750 \mathrm{~W}$. Measured results are compared with results calculation based on physical phenomena of boiling, condensation and natural convection heat transfer.
\end{abstract}

\section{Introduction}

The cooling device with heat pipe technology may be visualised as a long hollow pipe, bent and the ends joined to form a continuous loop, filled with working fluid and orientated in a vertical plane. If the one side of the loop is heated and the other side cooled, the average density of the fluid in the heated side is less than in the cooled side. An essentially hydrostatic pressure difference, as a result of the thermally induced temperature gradient between the hot and the cold sides, rives the fluid flows around the loop. The 'buoyancy' force, as it is often termed, driving the fluid is in turn counteracted by an opposing frictional force that tends to retard the flow [1].

Cooling device can transfer heat from the interior of a microelectronic system to a central location where space limitations are less stringent. The advantages that a cooling device with heat pipe technology enjoys over a conventional refrigeration system include: (1) absence of moving parts leading to a more reliable system operation, (2) increased choices for selecting a working fluid compatible with microelectronics chips since it does not have to go through a refrigeration cycle, (3) reducing the decomposition rate of the working fluid as the higher temperatures at the compressor discharge in a vapour compression refrigeration system are not encountered, (4) clean operation as no oil is circulated through the system. In comparison to pool boiling systems employing vapour space condensation, a heat pipe technology offers more flexibility in terms of providing a centralized condenser with different feed lines to individual evaporator stations. Further, with the addition of a liquid circulating pump in a cooling device, higher heat transfer coefficients associated with flow boiling systems could be realized [2].

\section{Design of cooling device}

The main parts of cooling device are:

- evaporator,

- condenser,

- pipeline,

- filling and closing valve,

- working fluid

The model of cooling device is shown on Fig. 1.The evaporator enables on the base of a phase change (boiling) of the working fluid an intensive heat removal from its surface. It has to be constructed so that it will prevent the leakage of the working fluid, maintain pressure differences in all the walls and enable heat transfer from the electronic component into the working fluid as well as a suitable distribution of liquid and vapour phases of the working fluid. When choosing the material suitable for the construction of evaporator, it is necessary to pay attention to its thermokinetic characteristics. To provide a minimal temperature drop between a heat source and evaporator, the evaporator material must feature high thermal conductivity. To prevent escape of vapour, it should not be porous. The material should have high strength but, at the same time, it should be easily machineable and compatible with the working fluid [3].

The evaporator body is a plate with dimensions $116 \mathrm{x}$ $206 \times 30 \mathrm{~mm}$. To provide the working fluid circulation there are two $12 \mathrm{~mm}$ openings drilled horizontally on the plate and connected with twenty one $6 \mathrm{~mm}$ vertical

* Corresponding author: patrik.nemec@,fstroj.uniza.sk 
connecting channels. They provide the transport of heated fluid vapour from the bottom to the top section of the evaporator. On the outer contact surface of the evaporator and electronic component there are three grooves with a mounted temperature sensor.

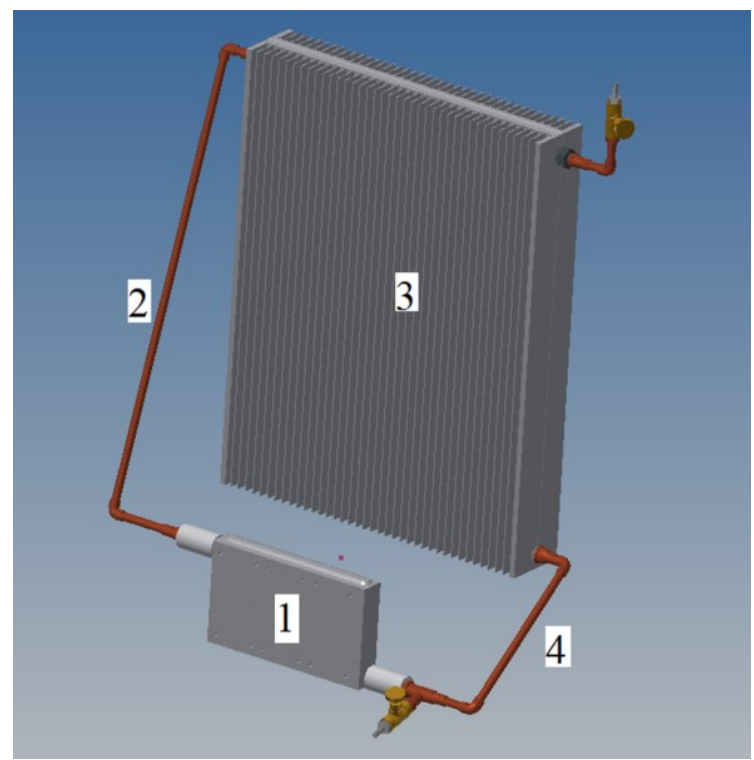

Fig. 1. Model of loop thermosiphon: 1 - evaporator, 2 vapour pipeline, 3 - condenser, 4 - liquid pipeline.

The condenser is proposed so that it was possible removed heat in to the surrounding by natural convection. It is created from two alumina fin coolers with dimensions $400 \times 480 \mathrm{~mm}$ and fin height $45 \mathrm{~mm}$. The each cooler has on the back side along the length ninety $7.5 \mathrm{~mm}$ deep and wide vertical grooves, and on the top and bottom two $10 \mathrm{~mm}$ deep and wide horizontal grooves. The cooler are soldered together on the back side and through the grooves can the working fluid flow down to the evaporator. This robust condenser construction allow remove high heat fluxes loaded to the evaporator [4].

The vapour pipeline and liquid pipeline connect evaporator with condenser and are transportation parts through the working fluid circulate in closed loop. The pipelines are made from copper material, due to its good installation properties and compatibility with almost all mediums used in heat pipe [5].

The working fluid in cooling device is Fluorinert FC 72 , due to its compatibility with most metals, low boiling temperature $\left(56^{\circ} \mathrm{C}\right)$ and solidification $\left(-90^{\circ} \mathrm{C}\right)$ and, first of all, due to its excellent dielectric characteristics [6].

\section{Experiment}

Fig. 2 show scheme to measure cooling efficiency of cooling device. Measurement consist from heat load of evaporator part and temperature detection on the evaporator part. On the evaporator part of the cooling device are fixed electric components connected to the DC power supply source and load heat flux to cooling device. Between surface of electronic element and evaporator surface are inserted three thermocouples (on the left side, on the right side and in the centre) to scanning electronic component temperature because the highest admissible temperature on the contact surface is $100{ }^{\circ} \mathrm{C}$. The temperature of the condenser is measured by two pair's temperature sensors. One thermocouple pairs is placed in the centre of condenser and second thermocouple pairs is placed on the top of condenser. On the condenser is connected pressure sensor to measure pressure in cooling device. All sensors are connected on the measuring unit where measured parameters convert and transmit signal to the PC. The measurement of the cooling efficiency of the cooling device was performed at input electric power $750 \mathrm{~W}$. Value $750 \mathrm{~W}$ was limited by the maximal electric power capacity of the DC power supply source. The measurement take place in the thermostatic chamber BINDER with regulation of ambient temperature in range -20 to $40{ }^{\circ} \mathrm{C}$.

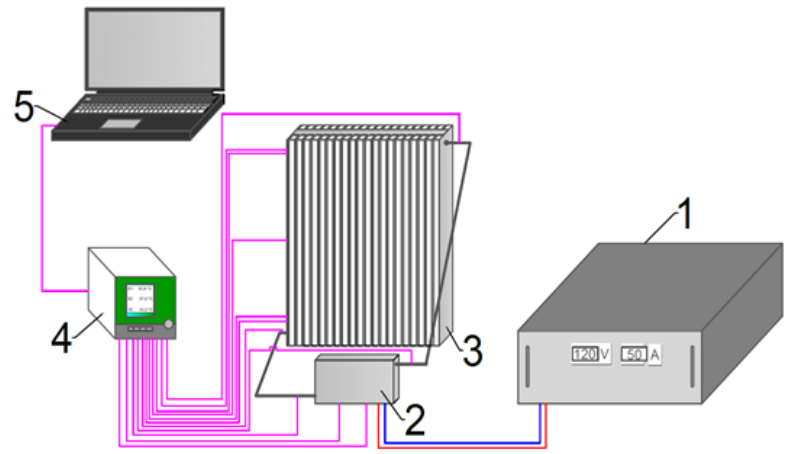

Fig. 2. Measuring scheme of loop thermosiphon cooling efficiency: 1 - power supply, 2 - evaporator, 3 - condenser, 4 - measuring centre, $5-\mathrm{PC}$.

\section{Mathematic calculation}

Basic of the mathematical calculation are heat transfer equations and criterial equations. The heat flux equates to the electrical power of the electronic components, reduced by the heat transfer into the air is transferred through the evaporator wall into the working fluid.

$$
Q=P e l=U I[W]
$$

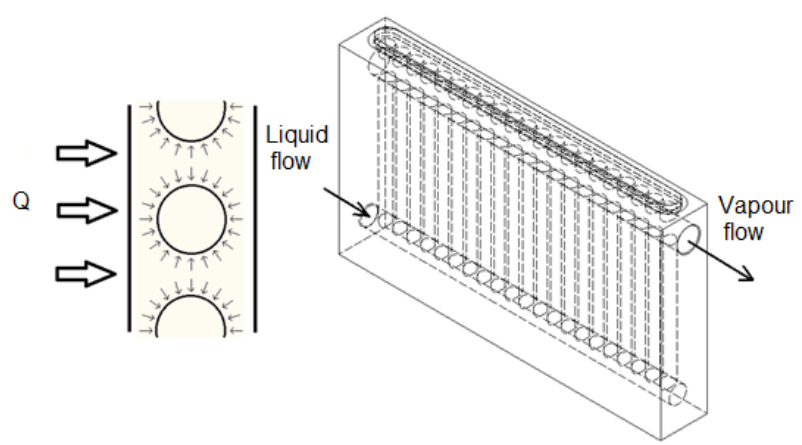

Fig. 3. Heat transfer in evaporation part of cooling device

The heat flux through the wall of the evaporator shown in Fig. 3 is determined by Furierer equation [7].

$$
Q=q_{s p} S[W]
$$

where $\mathrm{q}_{\mathrm{sp}}$ is heat flux density on the contact surface of the electronic components expressed by relationship 3 . 


$$
q_{s p}=\left(\lambda_{s v} / \delta_{s}\right)\left(t_{s p}-t_{s v}\right)\left[W / m^{2} \cdot K\right]
$$

where $\lambda_{\mathrm{sv}}$ is thermal conductivity of the evaporator wall, $t_{s p}$ is temperature of the outside surface of the evaporator wall, $t_{\mathrm{sv}}$ is temperature of the inside surface of the evaporator wall and $\delta_{\mathrm{s}}$ is evaporator wall thickness expressed by relationship 4.

$$
\delta_{s}=\delta_{v}-(\pi d / 8)[\mathrm{m}]
$$

The liquid is heated to the boiling point due to the heat flux, when phase changes from liquid to vapour occur. Heat flux is determined by Newton's relationship expressed by relationship 5 [8].

$$
Q=\alpha_{v} S_{v}\left(t_{s v}-t_{2,3}\right)[W]
$$

where $\alpha_{\mathrm{v}}$ heat transfer coefficient at liquid boiling, $\mathrm{S}_{\mathrm{v}}$ is inner surface of the evaporator wall and $t_{2,3}$ is temperature change of the state from liquid to vapour.

The heat transfer coefficient is then determined by Nusselt criterion according to the relationship 6 .

$$
N u=\alpha_{v} L / \lambda_{l}[-]
$$

where $\lambda_{1}$ is thermal conductivity of the liquid phase and $\mathrm{L}$ is characteristic dimension expressed by relationship 7 .

$$
L=\sigma \rho_{l} c_{p} T_{2,3} /\left(\rho_{v} l_{v}\right)^{2}[m]
$$

where $\sigma$ is surface tension of the liquid, $\rho_{1}$ is density of the liquid, $c_{p}$ is specific thermal capacity, $T_{2,3}$ is thermodynamic temperature change of the state from liquid to vapour, $\rho_{\mathrm{v}}$ is density of vapour and $1_{\mathrm{v}}$ is latent heat of vaporization.

Relations 8 and 9 express Nusellt criterion in pressure range of $1.10^{5}<\mathrm{p}<170.10^{5} \mathrm{~Pa}$ for bubble boiling at free flow convection [9].

$$
\begin{aligned}
& N u=0.0625 \operatorname{Re}_{B} 0.5 \operatorname{Pr}_{K}{ }^{0.333} 10^{-5} \leq \operatorname{Re}_{B} \leq 10^{-2} \\
& N u=0.125 \operatorname{Re}_{B} 0.65 \operatorname{Pr}_{K}^{0.333} 10^{-2} \leq \operatorname{Re}_{B} \leq 10^{4}
\end{aligned}
$$

where $\mathrm{Re}_{\mathrm{B}}$ is Reynolds criterion, expressed by relationship 10 and $\operatorname{Pr}_{\mathrm{K}}$ is Prandtl criterion expressed by relationship 11.

$$
\begin{gathered}
\operatorname{Re}_{B}=\omega_{v} L / v_{l}[-] \\
\operatorname{Pr}=v_{l} / \alpha_{l}[-]
\end{gathered}
$$

where $v_{1}$ is viscosity of the liquid and $\omega_{\mathrm{v}}$ is velocity generation of vapour affected by the heat flux density expressed by relation 12 . The vapour is then continuously fed through the pipeline from the evaporator to the condenser. In condenser vapour condenses and returns back in the liquid phase of condensate [10].

$$
\omega_{v}=q_{v} / \rho_{v} l_{v}\left[m \cdot s^{-1}\right]
$$

Then is temperature of the evaporator inner wall $t_{\mathrm{sv}}$ determined by the relationship 13 resulting from the relationship 5 .

$$
t_{s v}=\left(q_{v} / \alpha_{v}\right)+t_{2,3}\left[{ }^{\circ} \mathrm{C}\right]
$$

Temperature of contact area is determined by modification of the relationship 3 and expressed by relationship 14 [11].

$$
t_{s v}=q_{s p} / \lambda_{s v}+t_{s v}\left[{ }^{\circ} \mathrm{C}\right]
$$

\section{Results and discussion}

Under the term cooling efficiency is meaning cooling effectivity of the cooling device. The cooling effectivity is expressed by ability of the cooling device to remove heat from the electronic element connected on the evaporator depending on the ambient temperature. In Fig. 4 is shown measured and calculated evaporator temperature of cooling device depending on ambient temperature. There is seen that with increase of ambient temperature increase evaporator temperature. Increasing evaporator temperature mean that he cooling effectivity of the cooling device decrease. Even though the cooling device has high cooling effectivity, because is able to remove high heat flux from the electronic element and keep its temperature under admissible temperature of $100{ }^{\circ} \mathrm{C}$.

Comparison calculated and measured temperature of cooling device evaporator proves that the formulas chosen for evaporator temperature calculation in this case was correct and can be applied in other similar cases of heat transfer calculations.

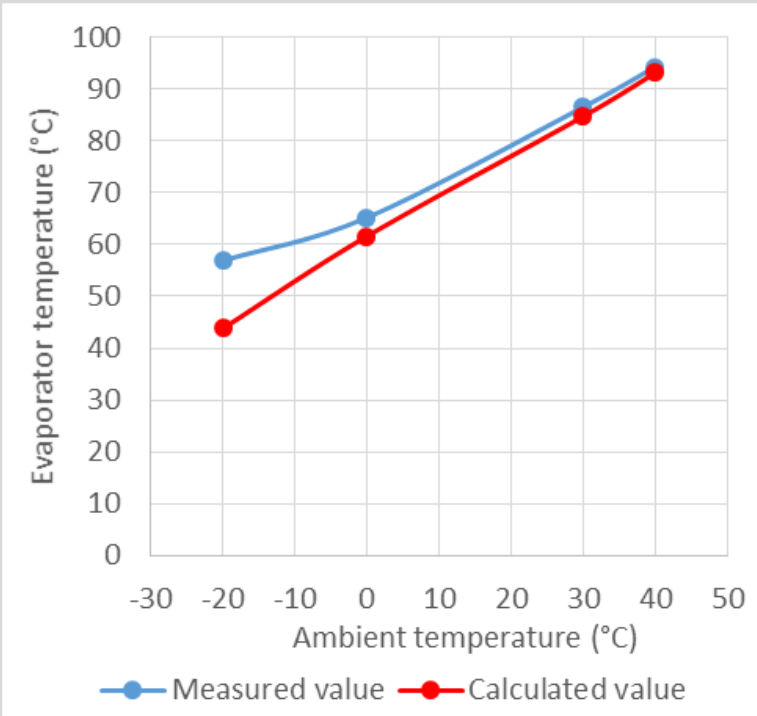

Fig. 4. Measured and calculated temperatures of cooling device evaporator depending on ambient temperature.

\section{Conclusion}

Experiment was aim at evaluation of evaporator temperature by measurement and calculation of cooling device working with a heat pipe technology. Conclusion of results comparison obtained by calculation and measurement is that cooling device is able operate in temperature range from -20 to $40{ }^{\circ} \mathrm{C}$ at high heat load and chosen formulas in the calculation can be applied in other similar cases of heat transfer calculations. 


\section{Acknowledgment}

This work is supported by the financial assistance of the projects APVV - 15-0778 "Limits of Radiative and Convective Cooling through the Phase Changes of Working Fluid in Loop Thermosyphon" and 042ŽU $4 / 2016$ "Cooling on the basis of physical and chemical processes.

\section{References}

1. C. Ruppersberg, R.T. Dobson, J. of Energy in South Africa, 18, 3 (2007)

2. J. Hartenstine, R. Boner III, J. Montgomery, T. Semenic, Proc. of ASME Inter PAC conf., (2007)

3. P. Pilat, M. Patsch, S. Papucik, M. Vantuch, AIP Conf. Proc., 1608 (2014)

4. F. Urban, M. Kubín, L. Kučák, AIP Conference Proceedings, 1608 (2014)

5. R. Lenhard, J. Jandačka, AIP Conf. Proc., 1558 (2013)

6. M. Holubčik, P. Ďurčanský, J. Jandačka, R. Nosek, Scient. World J., 2014 (2014)

7. D. V. Kozak, Yu. E. Nikolaenko, International Conference on Electronics and Information Technology, EIT 2016 - Conference Proceedings, (2016).

8. M. Mahdavi, S. Qiu, S. Tiari, Apl. Therm. Eng., 81 (2015)

9. L'. Šooš, P. Križan, M. Matúš, J. Beniak, Int. J. of Mechanics, 9 (2015)

10. T. Orzechowski, L. J. Orman, Polution Engineering, 38, 7 (2006)

11. J. Jandačka J. Mičieta, M. Holubčík, R. Nosek, Energy \& fuels, 31, 3 (2017) 